\title{
Psychiatry Investigation: 15 Years of Challenges
}

\author{
Heon-Jeong Lee, MD, PhD, Editor-in-Chief \\ Department of Psychiatry, Korea University College of Medicine, Seoul, Republic of Korea
}

Psychiatry Investigation, founded in 2004 as the official English journal of the Korean Neuropsychiatry Association (KNPA), celebrates its 15th anniversary of continued publication. Prof. Byoung-Hoon Oh was the founding Editor-inChief. Since then, excellent scholars such as Professors ChanHyung Kim (2005-2009), Jun-Soo Kwon (2009-2011), Chang-Uk Lee (2012-2015), and Dai-Jin Kim (2016-2017) have been the Editors-in-Chief, and have contributed greatly to the journal's success. ${ }^{1,2}$ Psychiatry Investigation was published biannually from 2004 to 2007, quarterly from 2008 to 2015 , bimonthly from 2016 to 2017 , and now becomes a monthly journal in 2018.

Psychiatry Investigation was listed in the Science Citation Index-Expanded (SCIE) by Thomson Reuters in April 2009, in the US National Institutes of Health PubMed index in December 2009, and in the Thomson Reuters Social Science Citation Index (SSCI) in April 2012, thanks to the profound contributions of the excellent editorial board members. According to the Web of Science database, its JCR 2016 impact factor was 1.406 , its $\mathrm{H}$-score was 22 , and the average citations per item was 5.26. Figure 1 shows trends in the sum of times Psychiatry Investigation was cited per year in recent years. ${ }^{3}$ These scores and the figure reflect Psychiatry Investigation's

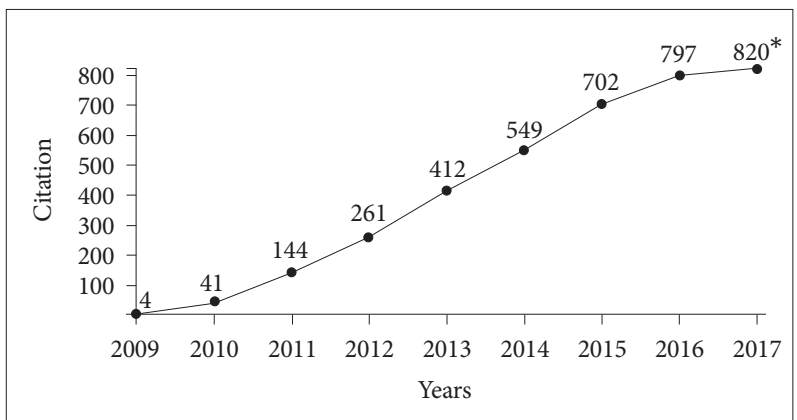

Figure 1. The trends in annual citations for Psychiatry Investigation (*data from Web of Science, accessed December 17, 2017). ${ }^{3}$

(c) This is an Open Access article distributed under the terms of the Creative Commons Attribution Non-Commercial License (http://creativecommons.org/licenses/bync/4.0) which permits unrestricted non-commercial use, distribution, and reproduction in any medium, provided the original work is properly cited.
Table 1. The distribution of the countries of the authors in Psychiatry Investigation between 2008 and 2017

\begin{tabular}{|c|c|c|}
\hline Countries & Number of articles & Percentages (\%) \\
\hline Korea & 544 & 76.30 \\
\hline USA & 93 & 13.04 \\
\hline Turkey & 44 & 6.17 \\
\hline Italy & 24 & 3.37 \\
\hline Japan & 22 & 3.09 \\
\hline Taiwan & 15 & 2.10 \\
\hline England & 12 & 1.68 \\
\hline India & 11 & 1.54 \\
\hline China & 11 & 1.54 \\
\hline Canada & 10 & 1.40 \\
\hline Australia & 8 & 1.12 \\
\hline Iran & 8 & 1.12 \\
\hline Spain & 5 & 0.70 \\
\hline Greece & 4 & 0.56 \\
\hline Thailand & 4 & 0.56 \\
\hline Brazil & 3 & 0.42 \\
\hline Germany & 3 & 0.42 \\
\hline Malaysia & 3 & 0.42 \\
\hline Norway & 3 & 0.42 \\
\hline Hungary & 2 & 0.28 \\
\hline Mexico & 2 & 0.28 \\
\hline Pakistan & 2 & 0.28 \\
\hline Slovakia & 2 & 0.28 \\
\hline Argentina & 1 & 0.14 \\
\hline Belgium & 1 & 0.14 \\
\hline Denmark & 1 & 0.14 \\
\hline Egypt & 1 & 0.14 \\
\hline Finland & 1 & 0.14 \\
\hline Israel & 1 & 0.14 \\
\hline Jordan & 1 & 0.14 \\
\hline Netherlands & 1 & 0.14 \\
\hline Poland & 1 & 0.14 \\
\hline Romania & 1 & 0.14 \\
\hline Serbia & 1 & 0.14 \\
\hline Singapore & 1 & 0.14 \\
\hline
\end{tabular}


achievements in the face of the challenges of the last 15 years.

Psychiatry Investigation is currently available online as an Open Access journal. The papers in Psychiatry Investigation can be searched for in PubMed, and researchers all over the world can access the full-text papers in the journal for free. Authors from over 35 countries have published their studies in Psychiatry Investigation (Table 1). This demonstrates the rise of the international status of the journal, but the significant portion of domestic papers in the previous issues shows that to be a true international journal, Psychiatry Investigation should become more internationalized. Up to this point, the development of Psychiatry Investigation has clearly been amazing. However, we cannot be satisfied. Psychiatry is a field of research that is expected to develop very rapidly in the future. We look forward to the role of Psychiatry Investigation in this development. Our new editorial team will do its best to promote the continued success of the journal.

\section{REFERENCES}

1. Oh BH. Upon publishing the official journal "Psychiatry Investigation". Psychiatry Investig 2004;1:12.

2. Kwon JS. Psychiatry investigation: the next step forward. Psychiatry Investig 2009;6:232.

3. Web of Science citation report for Psychiatry Investigation. Available at: http://apps.webofknowledge.com/summary.do?locale=en_US\&err orKey $=\&$ viewType $=$ summary\&product $=$ WOS\&search_mode $=$ Citati onReport\&colName $=$ WOS\&page $=1 \&$ qid $=2 \& S I D=D 4 O O g 2 C q 5 j S E l 2$ Y4cIk. Accessed December 17, 2017. 